\title{
Antenatal Bilateral Renal Vein Thrombosis with Combined Protein S and C Deficiency
}

Ksibi Imen ${ }^{1}$, Achour Radhouane ${ }^{2 *}$, Ben Jamaa Nadia ${ }^{3}$, Bennour Wafa', Cheour Meriem¹, Ben Amara Moez ${ }^{1}$, Ayari Fayrouz ${ }^{1}$, Ben Ameur N ${ }^{1}$, Aloui $\mathrm{Nadia}^{4}$, Neji KHaled${ }^{2}$, Masmoudi Aida $^{3}$ and Kacem Samia ${ }^{1}$

${ }^{1}$ Neonatal Intensive Care Unit, Center of Maternity and Neonatology of Tunis, University Tunis El Manar, Tunisia

${ }^{2}$ Department of Emergency, Center of Maternity and Neonatology of Tunis, University Tunis El Manar, Tunisia

${ }^{3}$ Department of Foetopathology, Center of Maternity and Neonatology of Tunis, University Tunis El Manar, Tunisia

${ }^{4}$ Department of Radiology, Center of Maternity and Neonatology of Tunis, University Tunis El Manar, Tunisia

\section{Abstract}

In neonates, renal vein thrombosis (RVT) is the second most common thrombosis. We report a case of antenatal bilateral RVT and we review the optimal therapeutic approaches.

I, a male newborn was admitted in the Neonatal Intensive Care Unit of the Center for Maternity and Neonatology of Tunis (CMNT) for respiratory distress and gross hematuria.

Initial laboratory work demonstrated renal impairment and Doppler renal ultrasound confirmed the diagnosis of bilateral RVT. Thrombophilia evaluation found a combined protein C and S deficiency. Thrombolysis was started with tissue plasminogen factor in association to anticoagulation with unfractionated heparin.

Renal vein thrombosis in neonates is a rare condition with a high morbidity rate. Thrombotic conditions may be associated with more severe clinical presentations. Currently, there is a lack of consensus concerning the management of RVT.

Keywords: Neonates; Renal vein thrombosis; Doppler; Anticoagulation; Heparin

\section{Introduction}

Neonates have a higher incidence of thrombosis when compared to older children $[1,2]$. Renal vein thrombosis (RVT) in neonates is the second most common thrombosis. It is a rare and severe condition associated to a high morbidity rate. Bilateral RVT is present in $30 \%$ of the cases [3,4]. We report a case of antenatal bilateral RVT and we review the optimal therapeutic approaches.

\section{Case Report}

An eutrophic male newborn at 38 weeks gestation, his mother is 25 years old, diabetic, gravida 2 para 2 . The baby was born from no consanguineous marriage, by normal vaginal delivery. APGAR score was respectively 9,10 and 10 at 1,5 and 10 min of life. There was no familial history of thromboembolism events. He was admitted in the Neonatal Intensive Care Unit (NICU) at birth for respiratory distress related to transient respiratory distress. He was voiding spontaneously with gross hematuria. He was also distended abdomen and bilateral palpable flank mass at birth. Blood pressure was within normal range for age. The remainder of his examination was unremarkable.

Initial laboratory work at our institution demonstrated normal platelet level at 162000 . CRP was $26 \mathrm{mg} / \mathrm{l}$. Creatinine at birth was 109 $\mu \mathrm{mol} / \mathrm{l}$. A renal ultrasound done four hours after birth, demonstrated retro-peritoneal hemorrhage, bilateral renal enlargement with diffusely increased echogenicity of the renal parenchyma. Doppler renal ultrasound detected high arterial resistance and reversed diastolic flow (Figure 1).

Antibiotics were given for suspected materno-foetal infection. Thrombophilia evaluation revealed a combined protein $\mathrm{C}$ and $\mathrm{S}$ deficiency (respectively level of 29 and 26\%). Cranial ultrasound was initially normal. Our patient was diagnosed with bilateral RVT associated with renal impairment. So thrombolysis was started using tissue plasminogen factor in association to anticoagulation with unfractionated heparin. Within 48hours, hematuria had subsided, the abdomen was less distended and the infant was voiding normally. Creatinine levels decreased. Streptokinase was stopped within three days. By the seventh day of life, clinical examination demonstrated poor neurologic function with left paralysis, so urgent cranial ultrasound was done and demonstrated right diffuse periventricular hyperechogenicity. Emergency cranial tomodensitometry revealed a stroke in the right middle cerebral artery territory (Figure 2). Renal Vein Thrombosis disappeared in the control of renal doppler ultrasound with persistence of bilateral renal enlargement that was more important in the left side; so continuous unfractioned heparin perfusion was maintained for one month then followed by low molecular weight heparin (LMWH) for a supplementary two month period. The treatment was then pursued by anti vitamin $\mathrm{K}$ during 3 months. By the third week of treatment, renal ultrasound was normal. He was discharged from the hospital at the age of 30 days. At the age of five months, DMSA scintigraphy found an unfunctionnal left kidney with a normal aspect of the right kidney. Renal ultrasound demonstrated right renal enlargement. The infant was followed up to the age of two years. At that age, he had a normal neurological examination.

\section{Discussion}

We report the case of a newborn male infant born with antenatal bilateral renal vein thrombosis (RVT) associated to a renal impairment.

*Corresponding author: Achour Radhouane, Maternity and Neonatalogy Center Tunis, Tunisia, Tel: +21698549398; E-mail: radhouane.a@live.com

Received September 19, 2016; Accepted October 05, 2016; Published October 15,2016

Citation: Imen K, Radhouane A, Nadia BJ, Wafa B, Meriem C, et al. (2016) Antenatal Bilateral Renal Vein Thrombosis with Combined Protein S and Deficiency. J Neonatal Biol 5: 233. doi: 10.4172/2167-0897.1000233

Copyright: @ 2016 Imen K, et al. This is an open-access article distributed under the terms of the Creative Commons Attribution License, which permits unrestricted use, distribution, and reproduction in any medium, provided the original author and source are credited. 


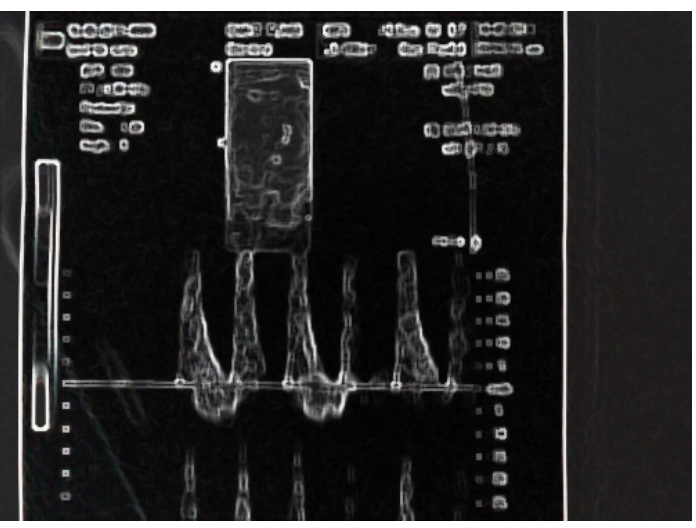

Figure 1: Doppler ultrasound of left kidney showing high arterial resistance and reversed diastolic flow.

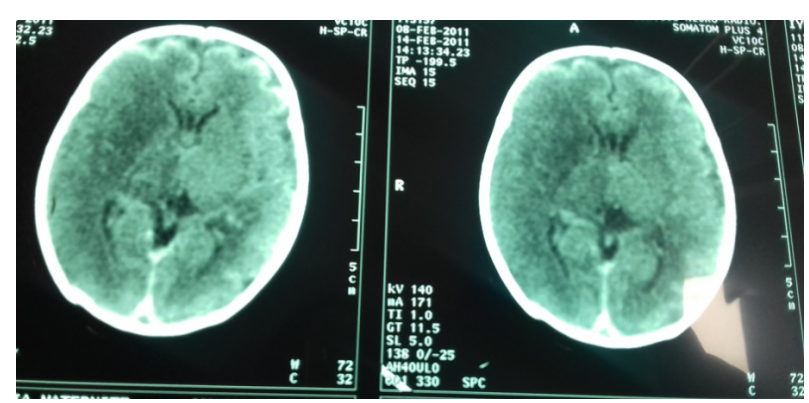

Figure 2: Cranial tomodensitometry: Stroke in the right middle cerebral artery territory.

This condition was related to a combined congenital deficit in protein $\mathrm{C}$ and protein S. Epidemiology about this subject (RVT in Neonates) is scarce. National and international registries for pediatric cases of thromboembolism were implemented in various countries [5-7]. Incidence of symptomatic neonatal thrombosis is 5.1 per 100.000 live births and 2.4 to 6.8 per 1000 neonatal intensive care admissions [810]. Renal vein thrombosis accounts for $20 \%$ of all thromboembolic events in newborns $[1,7,11]$. Prothrombotic disorders have been found in $43 \%$ to $67 \%$ of patients with RVT [8]. Several inherited prothrombotic conditions have been reported in association with neonatal RVT including factor V Leiden G 1691 A mutation, protein $\mathrm{C}$ and $\mathrm{S}$ deficiencies and the homozygous methylene tetra hydrofolate reductase (MTHFR) C 677 T polymorphisms [1,12-15] . Unfortunately, we did not screen our case for any gene mutations.Neonates were more frequently subject to thrombosis as they have decreased levels of natural anticoagulants such as protein $\mathrm{C}$, protein $\mathrm{S}$ and antithrombin, as well as low levels of fibrinolytic components such as plasminogen [1,16,17]. In an extensive thrombophilia evaluation of 28 newborns with RVT, $18 \%$ of these infants were found to have abnormally low levels of protein $\mathrm{C}$ and/or protein $S[1,12]$. Previous studies have reported that up to $80 \%$ of the affected neonates with RVT had coexisting risk factors $[1,11,12]$. Several risk factors were identified including a history of perinatal asphyxia, maternal diabetes mellitus, prematurity, dehydration and infection $[1,18]$. In our case, there is a history of maternal diabetes mellitus in addition to a deficiency in protein $\mathrm{C}$ and $\mathrm{S}$ factors.

Male neonates are more commonly affected than female neonates, representing $67,2 \%$ of the cases $[1,19]$. This fact could be explained by the greater risk of congenital renal malformations in males. The associated structural anomalies may predispose male infants to more risk of developing neonatal RVT [1,4]. Our case is also a male.

The three cardinal signs of RVT are macroscopic or microscopic hematuria, palpable flank mass and thrombocytemia. Our case had presented with macroscopic hematuria and palpable flank mass. This classic triad is observed in only $13-22 \%$ of the cases. Gross hematuria is present in $50 \%$ of RVT $[1,20]$. Other findings include hypertension, oliguria and renal insufficiency [20]. The incidence of neonatal hypertension remains low: less than $2 \%$. The most common cause of neonatal hypertension is renal-vascular disease including RVT [21]. Blood pressure in our case was within normal range. In a multicenter study from Canada, 56\% of the neonates had renal insufficiencies at onset $[1,12]$.Our patient had renal impairment. The majority of neonatal RVT are unilateral $(70,3 \%)$, with left-sided predominance $(63,6 \%)[1,19]$. Iyed had bilateral RVT. Thrombus extension into the inferior vena was found in approximately $40 \%$ of patients and $15 \%$ of them may have adrenal hemorrhage $[1,19]$. We did not find any thrombus extension into the inferior vena cava.

Imaging and mainly ultrasonography remains the cornerstone in confirming or ruling out RVT in neonates. Ultrasound findings vary with the time of onset, severity and extent of thrombus [1]. Cremin et al. proposed a loose staging system for RVT [1,22]. During the first week, renal enlargement is observed along with diffusely or focally increased echogenicity of the renal parenchyma. These findings were all observed in our case. Perivascular streaks are highly indicative for neonatal RVT $[1,23]$. During the second week, more proeminent and diffuse renal enlargement can be seen, with diffuse snow storm pattern of echogenicity and loss of cortico-medullary differenciation. In our case, left kidney continued to show enlargement in size. After the second week, kidney may be normal in appearance or became atrophic. Some calcifications may be seen in the kidney or within the vascular system. For our patient, control ultrasound was normal by the third week. Ciccone et al. had compared Contrast-Enhanced UltraSound (CEUS) with Echo Color Doppler (ECD) for the evaluation of renal artery stenosis in 120 hypertensive patients (mean age 55). They had concluded that CEUS is a promising technique and appears to be superior to ECD flow imaging for diagnosing renal artery stenosis. Other studies should be performed in infants and neonates [24].

During the acute phase, management of RVT required the collaboration approach of a team of neonatologists, haematologists, nephrologists and radiologists. The extent of RVT, whether there is unilateral or bilateral renal involvement, the presence or absence of renal impairment and the detection of a thrombophilic predisposition were considered before initiation of anticoagulation therapy. In 2008, the American College of Chest Physician (AACP) updated their evidence-based guidelines for antithrombotic therapy in newborns and children $[1,25]$. According to these guidelines, unfractionated or low molecular weight heparin (LMWH) therapies are recommended for the treatment of unilateral RVT with extension into the inferior vena cava. Bemiparin is a second-generation LMWH with the lowest molecular weight, the longest half-life and the highest anti-Factor Xa/ anti Factor IIa activity ratio. Several studies demonstrated its safety and efficacy even in special categories of patients such as children [26]. For bilateral RVT with or without renal impairment, the ACCP guidelines suggest initial thrombolysis with tissue plasminogen activator and anti-coagulation therapy with unfractionated heparin followed by continued anticoagulation with unfractionated or low molecular weight heparin. Supportive care or heparin therapy can be considered for the management of unilateral RVT in the absence of renal insufficiency. Other approaches are still controversial such as the deficit in the levels 
Citation: Imen K, Radhouane A, Nadia BJ, Wafa B, Meriem C, et al. (2016) Antenatal Bilateral Renal Vein Thrombosis with Combined Protein S and C Deficiency. J Neonatal Biol 5: 233. doi: 10.4172/2167-0897.1000233

Page 3 of 3

of natural anticoagulant factors such as anti-thrombin, protein $\mathrm{C}$ and S. These patients should benefit from replacement of these factors during the acute phase [1,27-29]. Our patient had bilateral RVT with renal impairment and had received thrombolysis and anticoagulation therapy.

Renal complications such as hypertension, renal atrophy and chronic renal insufficiency may persist after the acute phase $[1,30]$. During follow up, blood pressure should be monitored at every visit. As proteinuria is associated with poor cardiovascular outcomes, presence of protein in urine should prompt the treatment with either angiotensin converting enzyme (ACE) inhibitors or angiotensin receptor blockers (ARB) $[1,31]$. Renal ultrasound with Doppler should be performed at regular intervals. Infants with inherited prothrombotic disorders have an increased risk of recurrent RVT when compared to neonates without inherited thrombophilia, and they may require prolonged anticoagulation treatment to achieve maximal therapeutic benefit and to reduce the risk of long term morbidity.The infant was followed up to the age of two years. At that age, he had a normal neurological examination. Then he was followed in nephro-pediatric ward in order to detect any complications.

\section{Conclusion}

Neonatal RVT continues to pose significant challenges for neonatologists. Recent data suggest that infants with heritable thrombophilia are more exposed to in utero and/or bilateral involvement and recurrent thromboembolic disease. No consensus guidelines for the management of RVT are available. Further studies are necessary to clarify the short and long term effects of anticoagulation and thrombolytic therapies on renal outcomes.

\section{References}

1. Brandão LR, Simpson EA, Lau KK (2011) Neonatal renal vein thrombosis. Semin Fetal Neonatal Med 16: 323-328.

2. Andrew M, Monagle PT, Brooker L (2000) Thromboembolic complications during infancy and childhood. Hamilton, Ontario.

3. Bandari J, Dangie P, Tennyson LE, Correa AF, Cannon GM (2015) Large bladder clot - an unusal presentation of neonatal bilateral renal vein thrombosis - case report and review of literature .Urology 86: 811-813.

4. Winyard PJ, Bharucha T, De Bruyn R, Dillon MJ, van't Hoff W, et al. (2006) Perinatal renal venous thrombosis: Presenting renal length predicts outcome. Arch Dis Child Fetal Neonatal Ed 91: F273-278.

5. Saracco P, Bagna R, Gentilomo C, Magarotto M, Viano A, et al. (2016) Clinical data of neonatal systemic thrombosis. J Pediatr 171: 60-66.

6. van Ommen $\mathrm{CH}$, Heijboer $\mathrm{H}$, Büller HR, Hirasing RA, Heijmans $\mathrm{HS}$, et al (2001) Venous thromboembolism in childhood: A prospective two-year registry in The Netherlands. J Pediatr 139: 676-681.

7. Schmidt B, Andrew M (1995) Neonatal thrombosis: Report of a prospective Canadian and International registry. Pediatrics 96: 939-943.

8. Saxonhouse MA (2015) Thrombosis in the neonatal intensive care unit. Clin Perinatol 42: 651-673.

9. Andrew M, Paes B, Milner R, Johnston M, Mitchell L, et al. (1988) Development of the human coagulation system in the healthy premature infant. Blood 72 : 1651-1657.
10. van Elteren HA, Veldt HS, Te Pas AB, Roest AA, Smiers FJ, et al. (2011) Management and outcome in 32 neonates with thrombotic events. Int J Pediatr 2011: 217564

11. Kuhle S, Massicotte $P$, Chan A, Mitchell L (2004) A case series of 72 neonates with renal vein thrombosis. Data from the 1-800-NO-CLOTS Registry. Thromb Haemost 92: 729-733.

12. Marks SD, Massicotte MP, Steele BT (2005) Neonatal renal venous thrombosis: Clinical outcomes and prevalence of prothrombotic disorders. J Pediatr 146 811-816.

13. Zigman A, Yazbeck S, Emil S, Nguyen L (2000) Renal vein thrombosis: A 10 year review. J Pediatr Surg 35: 1540-1542.

14. Kosch A, Kuwertz-Bröking E, Heller C, Kurnik K, Schobess R, et al. (2004) Renal venous thrombosis in neonates: Prothrombotic risk factors and long-term follow-up. Blood 104: 1356-1360.

15. Proesmans W, van de Wijdeven P, Van Geet C (2005) Thrombophilia in neonatal renal venous and arterial thrombosis. Pediatr Nephrol 20: 241-242.

16. Corrigan JJ Jr, Sleeth JJ, Jeter M, Lox CD (1989) Newborn's fibrinolytic mechanism: Components and plasmin generation. Am J Hematol 32: 273-278.

17. van Teunenbroek A, Peters M, Sturk A, Borm JJ, Breederveld C (1990) Protein $\mathrm{C}$ activity and antigen levels in childhood. Eur J Pediatr 149: 774-778.

18. Messinger Y. Sheaffer JW. Mrozek J (2006) Renal outcome of neonatal renal venous thrombosis: review of 28 patients and effectiveness of fibrinolytics and heparin in 10 patients. Pediatrics 118: e1478-1484.

19. Lau KK, Stoffman JM, Williams S, McCusker P, Brandao L, et al. (2007) Neonatal renal vein thrombosis: Review of the English-language literature between 1992 and 2006. Pediatrics 120: e1278-1284.

20. Jernigan SM (2014) Hematuria in the new-born. Clin Perinatol 41: 591-603.

21. Batisky DL (2014) Neonatal hypertension. Clin Perinatol 41: 529-542.

22. Cremin BJ, Davey H, Oleszczuk-Raszke K (1991) Neonatal renal venous thrombosis: Sequential ultrasonic appearances. Clin Radiol 44: 52-55.

23. Metreweli C, Pearson R (1984) Echographic diagnosis of neonatal renal venous thrombosis. Pediatr Radiol 14: 105-108.

24. Ciccone MM, Cortese F, Fiorella A, Scicchitano P, Favale S (2011) The clinical role of contrast-enhanced ultrasound in the evaluation of renal artery stenosis and diagnostic superiority as compared to traditional echo-color-doppler flow imaging. Int Angiol 30: 135-139.

25. Monagle P, Chalmers E, Chan A (2008) Antithrombotic therapy in neonates and children: American College of Chest Physician Evidence-Based Clinical Practice Guidelines (8thedn).

26. Ciccone MM, Cortese F, Corbo F, Corrales NE, Al-Momen AK, et al. (2014) Bemiparin, an effective and safe low molecular weight heparin: a review. Vascul Pharmacol 62: 32-37.

27. Patnaik MM, Moll S (2008) Inherited antithrombin deficiency: A review. Haemophilia 14: 1229-1239.

28. ten Kate MK, van der Meer J (2008) Protein S deficiency: A clinical perspective. Haemophilia 14: 1222-1228.

29. De Carolis MP (2010) Use of protein C concentrate in neonatal period. Minerva Pediatr 62: 29-30.

30. Jobin J, O'Regan S, Demay G, Mongeau JG, Robitaille P (1982) Neonatal renal vein thrombosis - long-term follow-up after conservative management. Clin Nephrol 17: 36-40.

31. Segura J, Campo C, Ruilope LM (2004) Effect of proteinuria and glomerular filtration rate on cardiovascular risk in essential hypertension. Kidney Int Suppl: S45-49. 